\title{
Optimization of growth of two microalgal isolates for biofuel feedstock
}

\author{
N. M. Ali ${ }^{1}$, N. J. Tarin ${ }^{1}$, M. N. Mondol ${ }^{1 *}$, A. S. Chamon ${ }^{1}$, A. Aziz ${ }^{2}$ and M. M. Rahman ${ }^{1}$ \\ ${ }^{1}$ Department of Soil, Water and Environment, University of Dhaka, Dhaka-1000, Bangladesh \\ ${ }^{2}$ Department of Botany, University of Dhaka, Dhaka-1000, Bangladesh
}

\begin{abstract}
A research involving random isolation and characterization of naturally occurring microalgae in Bangladesh was carried out for assessing their potential for biofuel feedstock and other uses. Among the isolates, one identified as a green alga Chlamydomonas noctigama and another one as blue-green alga Nostoc spongiaeforme were grown in modified Chu-10D medium. The optimization of their growth was performed following incubation of the isolates under different levels of media concentration, temperature, $\mathrm{pH}$, light intensity and aeration. Both the species showed optimum growth in terms of total chlorophyll at a temperature of $25^{\circ} \mathrm{C}$. However, significant differences (at $5 \%$ level) in growth were observed for the isolates under other conditions. The optimum growth of Chlamydomonas noctigama was observed for the vitamin B1+B6, whereas there was no significant difference on growth of Nostoc spongiaeforme for any vitamin supplement. The optimum $\mathrm{pH}$ for the growth of Chlamydomonas noctigama and Nostoc spongiaeforme were 6.5 and 7.5 , light intensity $110 \mu \mathrm{Em}^{-2} \mathrm{~s}^{-1}$ and $70 \mu \mathrm{Em}^{-2} \mathrm{~s}^{-1}$, and media concentration $2 \mathrm{x}$ and $1 \mathrm{x}$ of normal concentration, respectively.
\end{abstract}

Keywords: Algae; Green alga; Blue-green alga; Chlamydomonas noctigama; Nostoc spongiaeforme; Optimization

\section{Introduction}

Algae are emerging to be one of the most promising longterm, sustainable sources of biomass and oils for fuel, food, feed, and other co-products. Algae efficiently use $\mathrm{CO}_{2}$, and are responsible for more than $40 \%$ of the global carbon fixation, with the majority of this productivity coming from marine microalgae. Algae can produce biomass very rapidly, with some species doubling in as few as $6 \mathrm{hrs}$, and many exhibiting two doublings per day (Hannon et al., 2010). All algae have the capacity to produce energy-rich oils, and a number of microalgal species have been found to naturally accumulate high oil levels in total dry biomass (Rodolfi et al., 2009).

Microalgae biofuels may provide a viable alternative to fossil fuels; however, this technology must overcome a number of hurdles before it can compete in the fuel market and be broadly deployed. These challenges include native strain identification and improvement, both in terms of oil productivity and crop protection, nutrient and resource allocation and use, and the production of co-products to improve the economics of the entire system (Pankaj and Awasthi, 2015).

Algae are easy to grow and cultivate anywhere with less energy requirements and using very few of the nutrients. The ideal growth conditions for microalgal cultures are strain specific and microalgae cultivation requires specific environmental conditions including temperature ranges, light intensities, mixing conditions, nutrient composition, and gas exchange. It is known that microalgae respond with physiological alterations to the environmental conditions where they grow (Schenk et al., 2008). This behavior can be viewed as a biotechnological attribute that can be manipulated in order to control the algal biochemical composition and growth, focusing on specific compounds and higher productivity. The need for clean and low-cost algae production demands for investigations on algal physiological response under different growth conditions.

A few thousand algal species are reported to occur in fresh water and marine environment in Bangladesh (Ahmed et al., 2008). However, the potential for these natural resources as biofuel feedstock and other probable uses are not assessed to that extent. Despite of its importance related to biodiesel production as reported in many countries of the world, quite a few studies have been conducted in Bangladesh with a very insignificant number of species such as Spirulina, Cholorococcum, Spirogyra sp. (Qudus and Halim, 2012) thus requiring a comprehensive work involving isolation,

*Corresponding author. e-mail: mondol-bangladesh@hotmail.com 
characterization and optimization of their growth and selection of algal strains as a potential feedstock. Therefore, the present investigation was undertaken in order to evaluate in vitro growth of some of the isolates under different conditions and their potential in terms of biomass production was assessed.

\section{Materials and methods}

\section{Isolation and Identification}

For isolation, water samples were randomly collected in plastic water bottles and also by dropper in glass vials containing modified Chu-10D medium from different natural and artificial water bodies (e.g. ponds, ditches, sprinklers etc.) located at Dhaka University campus area and Khulna region, during 01 March 2014 to 20 December 2014. Direct isolations were done by picking up single filament or single cell using Platinum wire loop or sterile Pasture pipette. In some cases, series of dilutions were made in sterile medium using homogenized suspension of natural algal samples.

Identification of both blue-green and green algae was carried out following cross matching of morphological characteris-

Habitat: Rice field
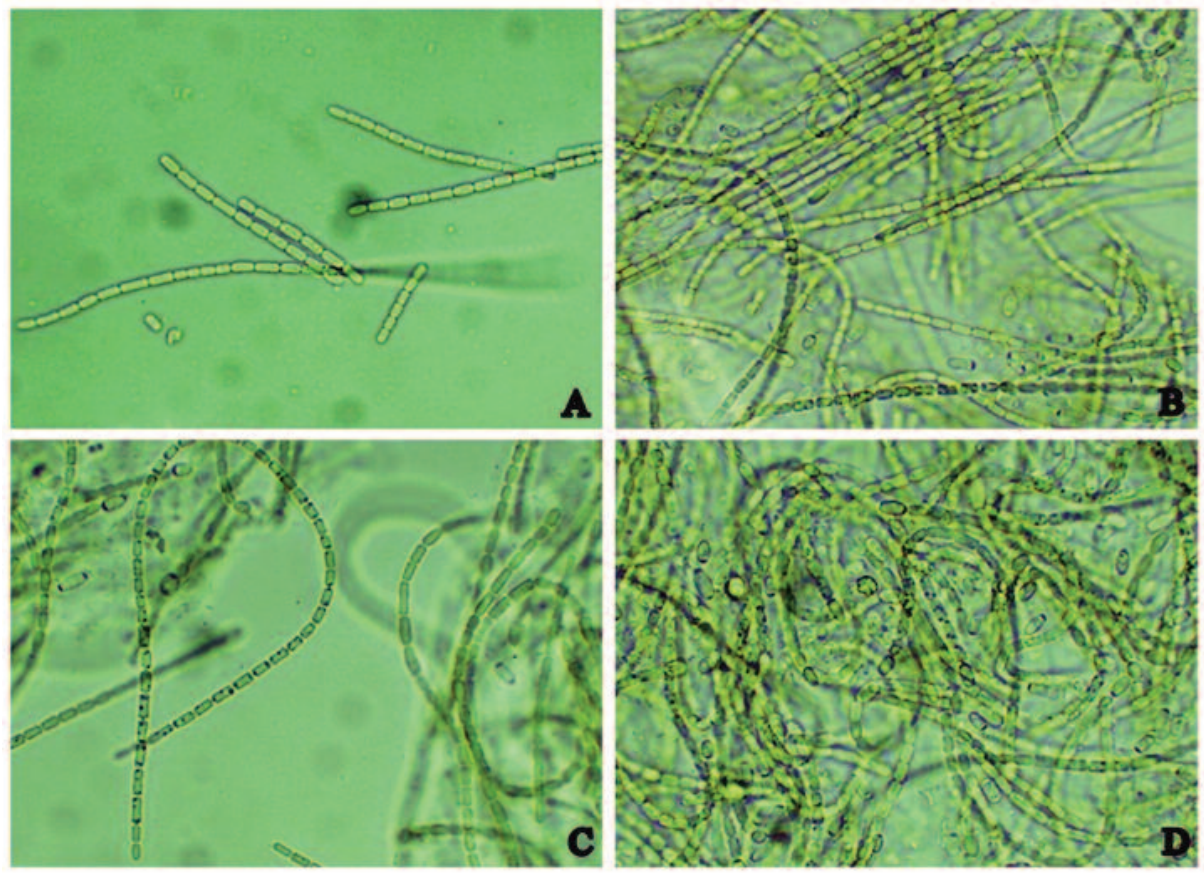

Figs. 1. A-D. Nostoc spongiaeforme, A. Hormogonia of various length, B. Fully developed filaments with low cyanophycin granules, C. Several developed filaments with intercalary heterocyst, D. Mature filaments with numerous granules tics as described by Siddiqui et al. (2007) and Ahmed et al. (2008).

Characteristics of blue-green alga (Nostoc spongiaeforme)

Class: Cyanophyceae

Order: Nostocales

Family: Nostocacae

Genus: Nostoc

Species: Nostoc spongiaeforme

\section{Description}

Colony globose when young, later expanding into an irregular gelatinous ball, 2-3 cm in diameter, blue-green in colour, dense peripherally with much contorted trichomes, central portion watery with less contorted trichomes. Trichomes 2.8$8.7 \mu \mathrm{m}$ wide. Cells 2.8-8.7 $\mu \mathrm{m}$ long. Heterocysts sub-spherical or oblong 4.2-5.8 $\mu \mathrm{m}$ wide, 4.8-8.4 $\mu \mathrm{m}$ long. Akinetes sub-spherical or ellipsoidal occurring in chains of 3-15, 45$8.0 \mu \mathrm{m}$ broad and 5.0-9.0 $\mu \mathrm{m}$ long, wall smooth. 
Characteristics of green alga (Chlamydomonas noctigama)

Class: Chlorophyceae

Order: Volvocales

Family: Chlamydomonadaceae

Genus: Chlamydomonas

Species: Chlamydomonas noctigama

Description

Cells spherical with true cell wall, flagella present. Chloroplasts parietal, massive cup-shaped, longitudinally ridged, pyrenoid usually one, in some cases two or three.

\section{Media Composition}

The liquid medium used in this study is not an absolute inorganic medium but with two organic compounds, the EDTA as a chelating agent and HEPES as a buffer.

\section{Sterilization}

All the required instruments were sterilized at $120^{\circ} \mathrm{C}$ temperature and $15 \mathrm{lb} / \mathrm{sq}$. inch $(10.35 \mathrm{~K} \mathrm{~Pa})$ pressure for $15 \mathrm{~min}$ utes.

Habitat: Pond, fountain, planktonic.
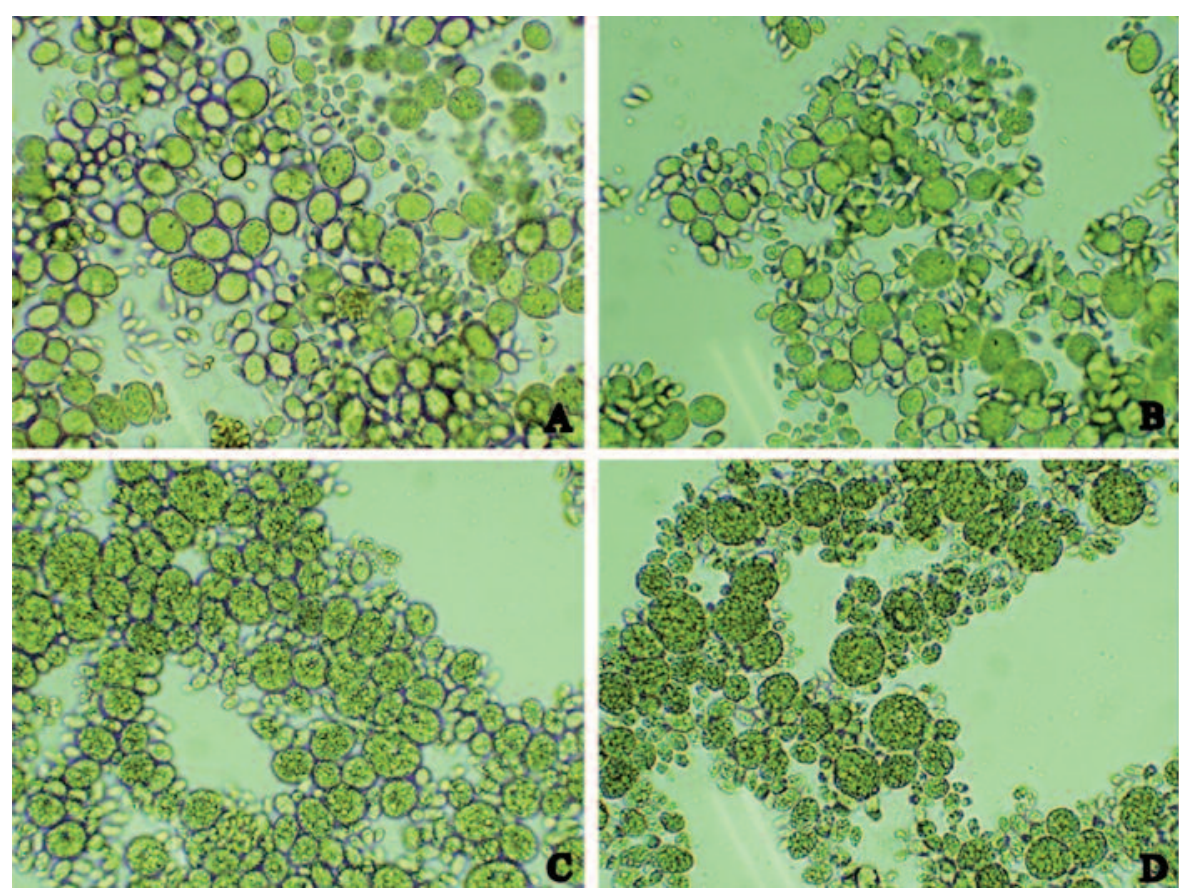

Figs. 2. A-D. Chlamydomonas noctigama, A-B. Early stage of mature non-granular cells, developing cells and zoospores, C-D. Mature cells and granular zoospores and with one distinct pyronoid in each cell

\section{Culturing of algae}

After identification, isolated microalgae were used as inoculants for algal monoculture. Identification of species followed by the genus was done with the 4, 8 and 15 days old monoculture. In vitro algal culture was done in modified Chu-10D culture medium (Sinclair and Whitton, 1977) incubated in the controlled growth room, at 23 to $28^{\circ} \mathrm{C}$ temperature in an average light flux of $71 \mu \mathrm{Em}^{-2} \mathrm{~s}^{-1}$.

\section{Maintenance and subculturing}

Stock cultures were maintained in $60 \mathrm{ml}$ liquid medium incubated standing in an average $25^{\circ} \mathrm{C}$ growth room under continuous light ( ca $40 \mu \mathrm{Em}^{-2} \mathrm{~s}^{-1}$ ). Subcultures to fresh medium were made after about three months. Stocks for experimental purposes were maintained at $32^{\circ} \mathrm{C}$ under continuous light of average $71 \mu \mathrm{Em}^{-2} \mathrm{~s}^{-1}$. 
Table I. Composition of modified Chu-10D medium ( $\mathrm{mg} \mathrm{l}^{-1}$ of salts) used in the present study with Chu-10D of Sinclair and Whitton (1977)

\begin{tabular}{|c|c|c|c|}
\hline \multicolumn{2}{|c|}{ Salts } & Modified Chu-10D medium (Aziz and Whitton 1987) & Chu-10D \\
\hline \multicolumn{2}{|c|}{$\mathrm{Ca}\left(\mathrm{NO}_{3}\right)_{2} \cdot 4 \mathrm{H}_{2} \mathrm{O}$ (for $\mathrm{GA}$ ) } & 57.6 & 57.6 \\
\hline \multicolumn{2}{|c|}{$\mathrm{KH}_{2} \mathrm{PO}_{4}$} & 7.8 & 7.8 \\
\hline \multicolumn{2}{|c|}{$\mathrm{MgSO}_{4} \cdot 7 \mathrm{H}_{2} \mathrm{O}$} & 25 & 25 \\
\hline \multicolumn{2}{|c|}{$\mathrm{Na}_{2} \mathrm{SiO}_{3} .5 \mathrm{H}_{2} \mathrm{O}$} & - & 10.88 \\
\hline \multicolumn{2}{|c|}{$\mathrm{NaHCO}_{3}$} & 23.73 & 15.85 \\
\hline \multicolumn{2}{|c|}{$\mathrm{CaCl}_{2} \cdot 2 \mathrm{H}_{2} \mathrm{O}$ (for BGA) } & 35.84 & - \\
\hline \multirow[t]{2}{*}{ Fe-EDTA } & $\mathrm{FeCl}_{3} \cdot 6 \mathrm{H}_{2} \mathrm{O}$ & - & \\
\hline & $\mathrm{Na}$ EDTA. $2 \mathrm{H}_{2} \mathrm{O}$ & 0045 & $\begin{array}{l}3.18 \\
0.045\end{array}$ \\
\hline \multirow{6}{*}{ Micronutrients } & $\mathrm{MnCl}_{2} \cdot 4 \mathrm{H}_{2} \mathrm{O}$ & 0.045 & 0.045 \\
\hline & $\mathrm{NaMoO}_{4} \cdot 2 \mathrm{H}_{2} \mathrm{O}$ & $\begin{array}{l}0.007 \\
0.056\end{array}$ & 0.056 \\
\hline & $\mathrm{ZnSO}_{4} \cdot 7 \mathrm{H}_{2} \mathrm{O}$ & $\begin{array}{c}0.056 \\
0.02\end{array}$ & 0.02 \\
\hline & $\begin{array}{l}\mathrm{CuSO}_{4} .5 \mathrm{H}_{2} \mathrm{O} \\
\mathrm{CoSO} .7 \mathrm{H}_{2} \mathrm{O}\end{array}$ & 0.02 & 0.01 \\
\hline & $\mathrm{H}_{3} \mathrm{BO}_{4}$ & 0.72 & 0.72 \\
\hline & & ca 59.0 & - \\
\hline
\end{tabular}

*added as $1 \mathrm{M} \mathrm{NaOH}$ solution ( $c a 1.48 \mathrm{ml} \mathrm{l}^{-1}$ medium) during buffering with HEPES to $\mathrm{pH} 7.2$

Table II. Composition of modified Chu-10D medium ( $\mathrm{mg} \mathrm{l}^{-1}$ of elements) of Aziz and Whitton (1987) used in the present study and comparison with Chu-10D of Sinclair and Whitton (1977)

\begin{tabular}{lcc}
\hline Elements & Modified Chu-10D medium & Chu-10D \\
\hline $\mathrm{N}$ (only for GA) & 6.83 & 6.83 \\
$\mathrm{P}$ & 1.78 & 1.78 \\
$\mathrm{~K}$ & 2.24 & 2.24 \\
$\mathrm{Na}$ & $\mathrm{ca} 40.0^{*}$ & 6.69 \\
$\mathrm{Ca}$ & 9.78 & 9.78 \\
$\mathrm{Mg}$ & 2.47 & 2.47 \\
$\mathrm{~S}$ & 3.25 & 3.25 \\
$\mathrm{Fe}$ & 0.5 & 0.5 \\
$\mathrm{Si}$ & - & 1.44 \\
$\mathrm{Cl}$ & 17.26 & 0.016 \\
$\mathrm{Mn}$ & 0.012 & 0.012 \\
$\mathrm{Mo}$ & 0.0028 & 0.0028 \\
$\mathrm{Zn}$ & 0.013 & 0.013 \\
$\mathrm{Cu}$ & 0.005 & 0.005 \\
$\mathrm{Co}$ & 0.002 & 0.002 \\
$\mathrm{~B}$ & 0.125 & 0.125 \\
\hline
\end{tabular}

*Na concentration increased from 6.69 to $40.0 \mathrm{mg} \mathrm{l}^{-1}$ due to the addition of $1 \mathrm{M} \mathrm{NaOH}$ solution ( $c a 1.48 \mathrm{ml} \mathrm{l}^{-1}$ ) during buffering with HEPES to $\mathrm{pH} 7.2$
Estimation of growth

Total chlorophyll and optical density (O.D.) have been used to estimate growth. During early stage of growth, the whole contents of each flask were used for either total chlorophyll or O.D.

Chlorophyll $a$ (for blue-green alga) was estimated by following the procedure based on the recommendations of Marker et al. (1980).

Chlorophyll $a$ and $b$ can be calculated by following formulae according to APHA (American Public Health Association), 1985.

By measuring the optical density at $750 \mathrm{~nm}$ growth was estimated using a spectrophotometer as described by Rodolfi et al., 2009. During early stage of growth, the whole contents of each flask were used for O.D.

Optimization of growth conditions

The need for clean and low-cost algae production demands for investigations on algal physiological response under different growth conditions. Experiments were carried out in batch culture under continuous light. In the growth room 
illumination was provided by white fluorescent tubes (average $71 \mu \mathrm{Em}^{-2} \mathrm{~s}^{-1}$ ) above and below the alga. The flasks were usually randomly rearranged at $24 \mathrm{~h}$ interval. The temperature was set at a range of 24 to $26{ }^{\circ} \mathrm{C}$.

$p H$

Seven $\mathrm{pH}$ values (i.e. 5.0, 5.5, 6.0, 6.5, 7.0, 7.5 and 8.0) for GA and five $\mathrm{pH}$ values (i.e. 6.5, 7.0, 7.5, 8.0 and 8.5) for BGA had been used to find out the optimum $\mathrm{pH}$ value for respective algal growth in the medium.

\section{Temperature}

The growth of both GA and BGA was observed at four different temperature (i.e. $20,25,30$ and $35^{\circ} \mathrm{C}$ ) to find out optimum temperature for respective algal growth in the medium.

\section{Light intensity}

Five light intensities (i.e. 30, 50, 70, 90 and $110 \mu \mathrm{Em}^{-2} \mathrm{~s}^{-1}$ ) had been used to find out the optimum light intensity for the growth of selected algal strains.

\section{Vitamin supplements}

Four vitamin solutions, individually (i.e. B1, B6, B7, B12) and in six combinations (i.e. $\mathrm{B} 1+\mathrm{B} 6, \mathrm{~B} 1+\mathrm{B} 7, \mathrm{~B} 1+\mathrm{B} 12$, $\mathrm{B} 7+\mathrm{B} 12, \mathrm{~B} 1+\mathrm{B} 7+\mathrm{B} 12$ and $\mathrm{B} 1+\mathrm{B} 6+\mathrm{B} 7+\mathrm{B} 12)$ had been used to find out the effect of vitamin for two algal growths in the medium.

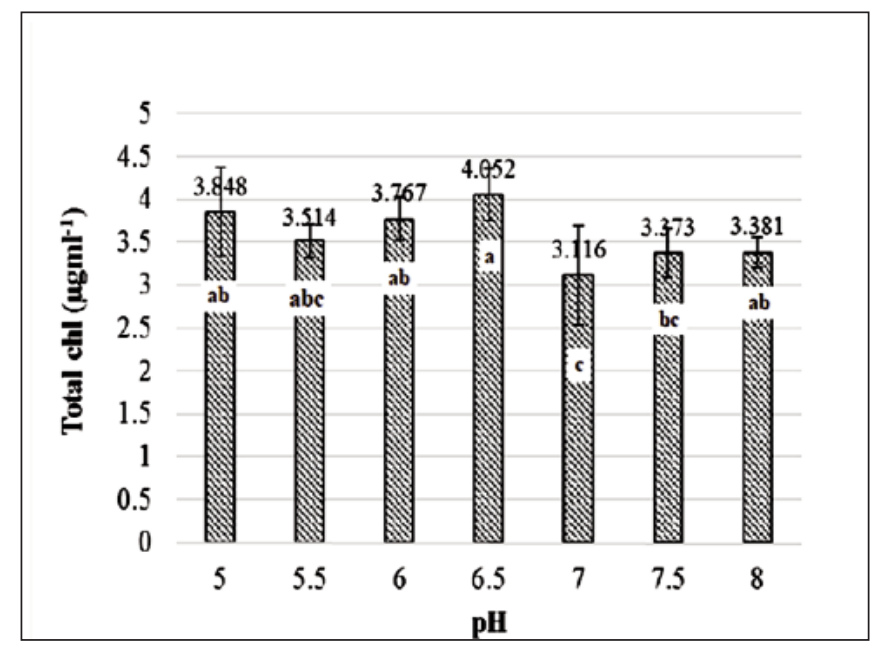

Fig. 3. Effect of pH on the growth as total chlorophyll (chl $a$ and $b$ ) of Chlamydomonas noctigama

\section{Media concentration}

Three concentrations of media, i.e. $1 \mathrm{x}, 1.5 \mathrm{x}$ and $2 \mathrm{x}$ had been used to find out the optimum concentration of media for two algal growths.

\section{Air bubbling}

The effect of air bubbling on the growth of the selected microalgae had been observed by supplying air-bubbles in the culture-flasks with control at the flux of $8 \mathrm{Lmin}^{-1}$ and the pressure of $0.0067 \mathrm{M} \mathrm{Pa}$ using a SOBO aquarium air pump (SB-348 A).

\section{Results and discussion}

The effect of different growth conditions, namely $\mathrm{pH}$, light intensity, temperature, nutrient concentration in growth medium, vitamins and air-bubbles supply were evaluated to optimize the conditions of growth as well as the production of biomass for selected microalgal samples (Chlamydomonas noctigama and Nostoc spongiaeforme). The standard deviation was done to measure the sample fluctuation, analysis of variance (ANOVA) of the data was computed to determine the F-value and the test of significance was computed by Duncan's Multiple Range Test (DMRT), using IBM SPSS Statistics V.22.

\section{$p H$}

The $\mathrm{pH}$ can affect the growth of microorganisms and each species has a definite $\mathrm{pH}$ growth range and $\mathrm{pH}$ growth opti-

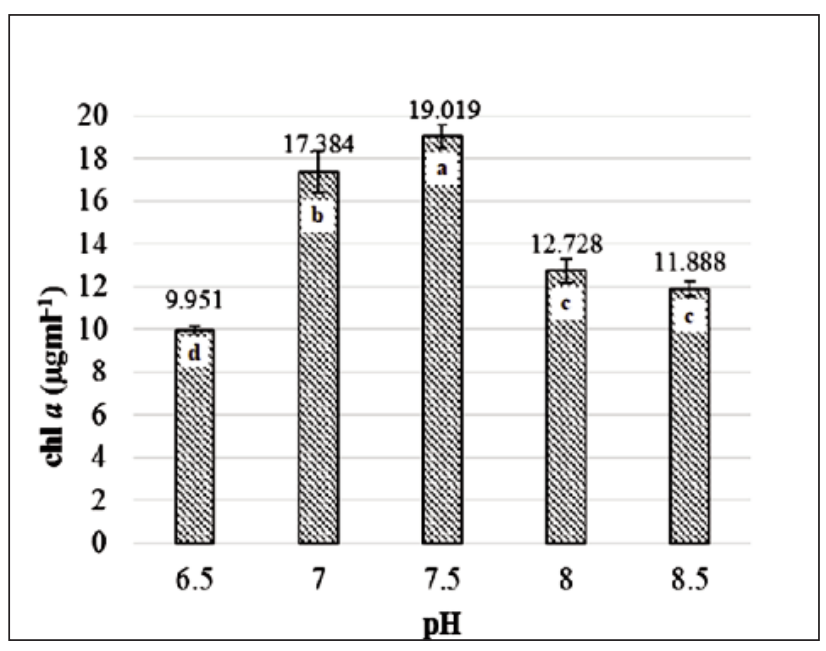

Fig. 4. Effect of $\mathrm{pH}$ on the growth as chlorophyll (chl a) of Nostoc spongiaeforme 
mum. Extreme pH conditions influence photosynthesis, growth and nutrient assimilation in algae (Gensemer et al., 1993). The effect of different $\mathrm{pH}$ values on growth of Chlamydomonas noctigama (as total chlorophyll) and Nostoc spongiaeforme (as chlorophyll a) was presented in Fig. 3 and 4, respectively. The result was statistically significant at 5\% level. This means $\mathrm{pH}$ had significant influence on the growth of both algal species.

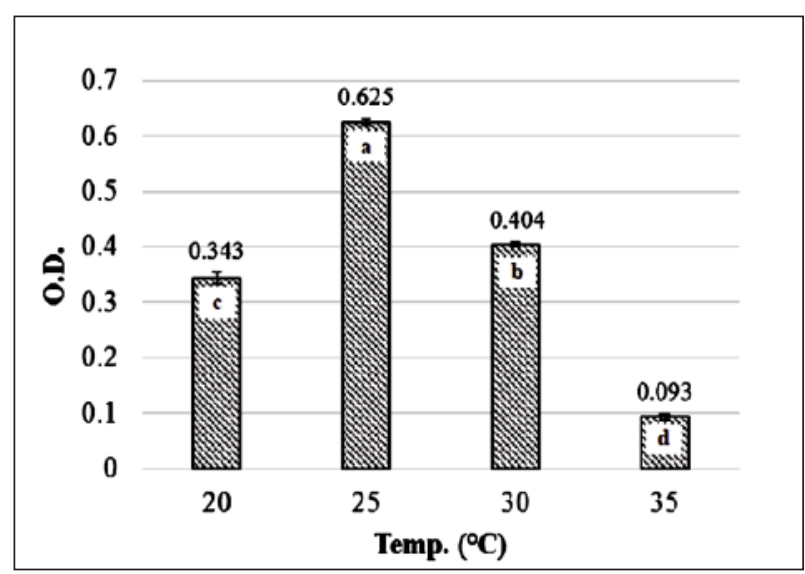

Fig. 5. Effect of temperature on the growth as O.D. of Chlamydomonas noctigama

The highest growth $\left(4.052 \mu \mathrm{gml}^{-1}\right.$ ) and the lowest growth (3.116 $\mu \mathrm{gml}^{-1}$ ) as total chlorophyll (chlorophyll a and b) per $\mathrm{ml}$ of Chlamydomonas noctigama were found at $\mathrm{pH} 6.5$ and pH 7.0, respectively. The highest growth was slightly different from the growth at $\mathrm{pH} 7.0,5.5,6.0$ and 8.0, whereas the lowest growth was slightly different from the growth at $\mathrm{pH}$ 5.5 and 7.5 .

The optimum growth of Chlamydomonas noctigama in this research was determined at $\mathrm{pH} 6.5$ which is near about the $\mathrm{pH}$ condition of the habitat from which the species was isolated. Skjanes et al. (2008) also found optimum $\mathrm{pH}$ for the growth of Chlamydomonas noctigama collected from fresh water as 6.5 .

The highest growth (19.019) and the lowest growth (9.951) as chlorophyll a per $\mathrm{ml}$ of Nostoc were found at $\mathrm{pH} 7.5$ and $\mathrm{pH} 6.5$, respectively. The highest and the lowest growth were statistically different from all other growth.

The optimum $\mathrm{pH}$ range for Nostoc sp. was reported by Rodriguez et al. (1986) as 6.4-8.2 which was almost similar to this research. Granhall (1975) reported optimum $\mathrm{pH}$ for the activity of Nostoc punctiforme as 7.6 which was also very close to the findings of this research. Lang et al. (2008) found optimum growth of Nostoc sp. at pH 7.0.

\section{Temperature}

The effect of different temperature on growth of Chlamydomonas noctigama and Nostoc spongiaeforme as O.D. (750 nm) was statistically different from each other.

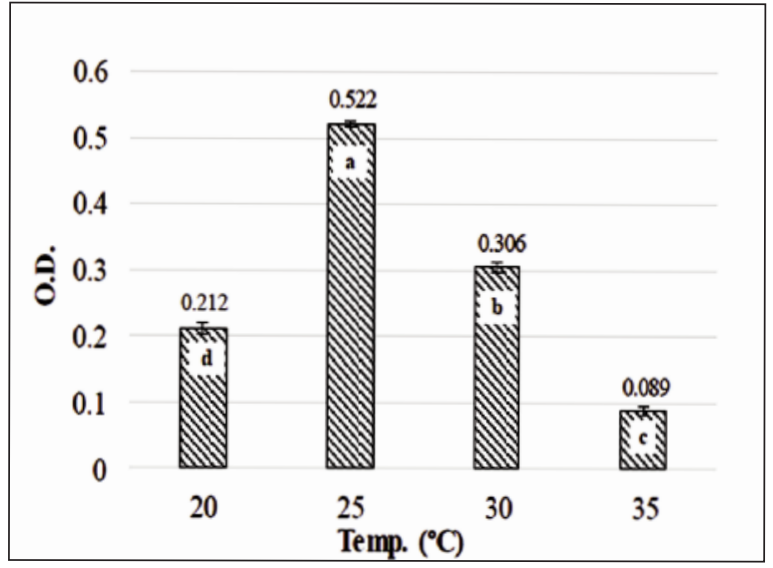

Fig. 6. Effect of temperature on the growth as O.D. of Nostoc spongiaeforme

The highest and lowest growth as O.D. (750 nm) was found at the temperature of $25^{\circ} \mathrm{C}$ and $35^{\circ} \mathrm{C}$, respectively for both of the isolates.

From the result of the study the optimum temperature Chlamydomonas noctigama is $25^{\circ} \mathrm{C}$ which is similar to that of Chlamydomonas reinhardtii found by Akimoto et al. (1997). Harris (2009) reported that the usual laboratory species of Chlamydomonas grow well in the range of 20$25^{\circ} \mathrm{C}$. Pocock et al. (2004) used $29^{\circ} \mathrm{C}$ as optimum temperature for the culture of Chlamydomonas noctigama in Bold's basal medium. The result varies might be due to the change in medium.

The growth increases with the increase in temperature up to its optimum and then declines with the increase in temperature. The optimum growth condition for the selected bluegreen alga was achieved at temperature of $25^{\circ} \mathrm{C}$ which is similar to the finding of Li-Juan et al. (2011) on Nostoc commune. Spencer et al. (2011) found optimum growth of Nostoc spongiaeforme at $26^{\circ} \mathrm{C}$ on BG-11 medium. 


\section{Light intensity}

The effect of different light intensities at $0 \mathrm{hr}$ on the growth as O.D. (750 nm) of Chlamydomonas noctigama and Nostoc spongiaeforme was not statistically significant but the growth after $72 \mathrm{hr}$ was statistically different from each other.

The highest growth (0.727) and lowest growth (0.621) were found at the light intensity of 110 and $30 \mu \mathrm{Em}^{-2} \mathrm{~s}^{-1}$ for Chlamydomonas noctigama and of 70 and $30 \mu \mathrm{Em}^{-2} \mathrm{~s}^{-1}$. for Nostoc spongiaeforme. The highest growth of Chlamydomonas noctigama had no statistical difference from the growth at the light intensity of $90 \mu \mathrm{Em}^{-2} \mathrm{~s}^{-1}$.

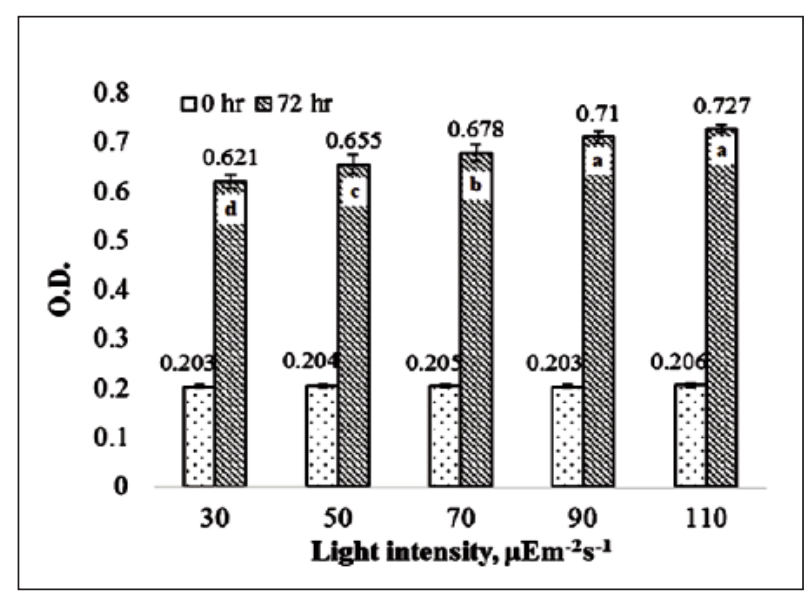

Fig. 7. Effect of light intensity on the growth as O.D. of Chlamydomonas noctigama

The result showed an increase in growth of Chlamydomonas noctigama with increasing light intensity. The optimal average light intensity for $\mathrm{H}_{2}$ production in Chlamydomonas reinhardtii was found by Laurinavichene et al. (2004) as 30-

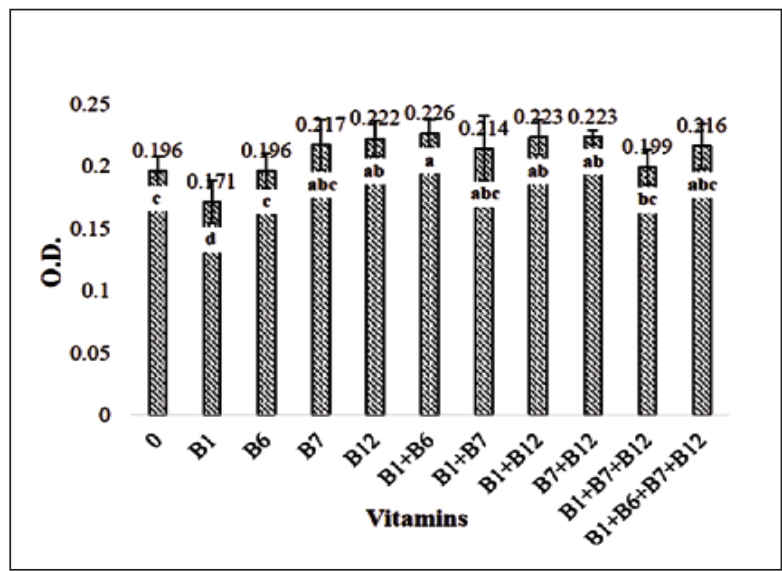

Fig. 9. Effect of vitamins on the growth as O.D. of Chlamydomonas noctigama
$40 \mu \mathrm{Em}^{-2} \mathrm{~s}^{-1}$. For, Nostoc spongiaeforme the result showed an increase in growth with increasing light intensity up to 70 $\mu \mathrm{Em}^{-2} \mathrm{~s}^{-1}$ and then declines. So, optimum light intensity for the growth of this blue-green alga is $70 \mu \mathrm{Em}^{-2} \mathrm{~s}^{-1}$. But Spencer et al. (2011) found that $227 \mu \mathrm{Em}^{-2} \mathrm{~s}^{-1}$. of light was optimum for the growth of Nostoc spongiaeforme on BG-11 medium. The reason behind this might be the variation among the growth media. Besides, it is the limitation of the research that it was not feasible to provide light intensity more than $110 \mu \mathrm{Em}^{-2} \mathrm{~s}^{-1}$ in the growth room.

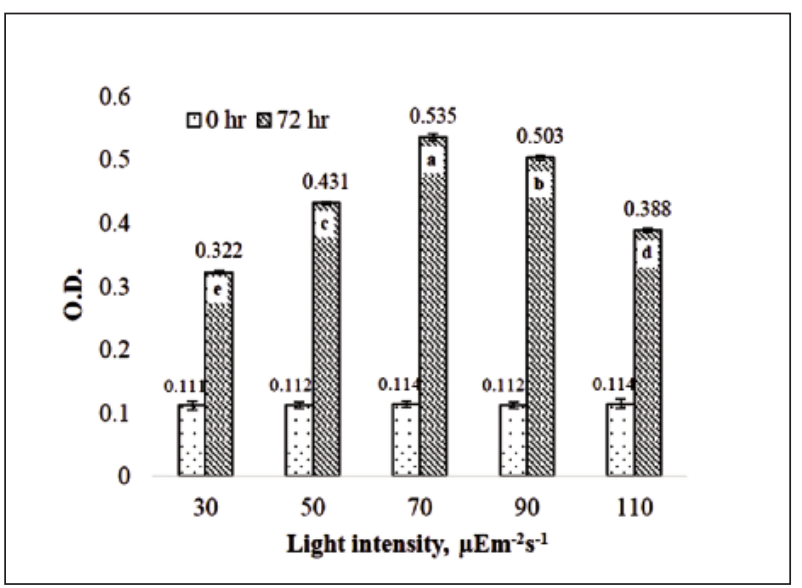

Fig. 8. Effect of light intensity on the growth as O.D. of Nostoc spongiaeforme

Vitamin supplements

The effect of different vitamin on growth of Chlamydomonas noctigama and Nostoc spongiaeforme as O.D. (750 nm) was presented in Fig. 9 and 10, respectively.

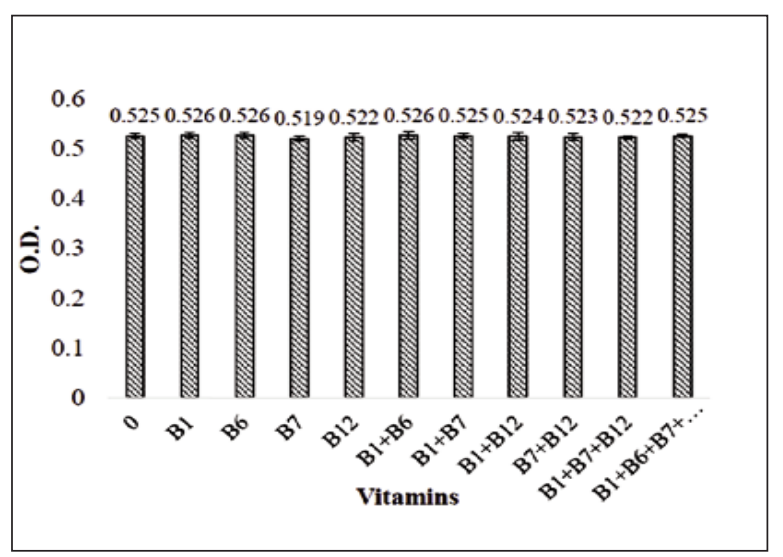

Fig. 10. Effect of vitamins on the growth as O.D. of Nostoc spongiaeforme 
The result was statistically significant for Chlamydomonas noctigama and not statistically significant for Nostoc spongiaeforme at 5\% level as the growth had no statistical difference to each other and also to the control.

The result showed that the highest growth $(0.226)$ and the lowest growth (0.171) of Chlamydomonas noctigama were found at the vitamin B1+B6 and B1, respectively. The highest growth was slightly different from the growth at B7, B12, $\mathrm{B} 1+\mathrm{B} 7, \mathrm{~B} 1+\mathrm{B} 12, \mathrm{~B} 7+\mathrm{B} 12$ and $\mathrm{B} 1+\mathrm{B} 6+\mathrm{B} 7+\mathrm{B} 12$.

Croft et al. (2006) found that many algal species require exogenous cobalamin (vitamin B12), thiamine (vitamin B1) or biotin (vitamin B7) for growth. In this study, it had been found that the addition of vitamin B1+B6 in the media had a positive effect on the growth of Chlamydomonas noctigama. McVeigh and Brown (1954) found stimulating effect on the growth of Chlamydomonas noctigama after including vitamin B12 with the medium.

Kartz and Myers (1953) stated that numerous attempts to elicit a growth response from Nostoc muscorum by the addition of vitamins to a culture medium had proved fruitless. However, the addition of vitamins in the large scale commercial system might be proved to be advantageous.

\section{Media concentration}

The effect of different media conc. on growth of Chlamydomonas noctigama and Nostoc spongiaeforme as O.D. $(750 \mathrm{~nm})$ at $0 \mathrm{hr}$ on the growth of both isolates was not

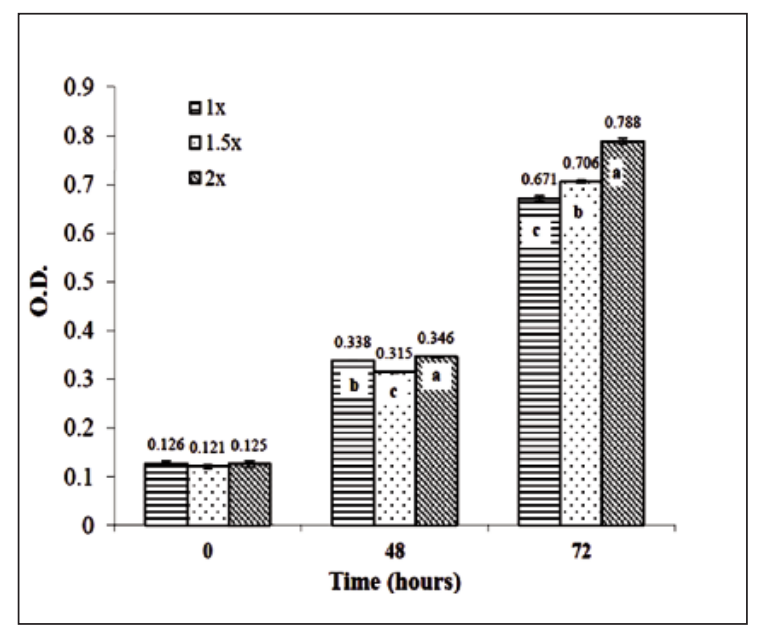

Fig. 11. Effect of nutrient concentration in medium on the growth as O.D. of Chlamydomonas noctigama statistically significant. But the result was statistically significant for both of them at $48 \mathrm{hr}$ and $72 \mathrm{hr}$.

The highest growth (0.346) and the lowest growth (0.315) as O.D. (750 nm) of Chlamydomonas noctigama were found at $2 \mathrm{x}$ and $1.5 \mathrm{x}$, respectively after $48 \mathrm{hr}$. whereas the highest growth $(0.788)$ and the lowest growth $(0.671)$ as O.D. were found at $2 \mathrm{x}$ and $1 \mathrm{x}$, respectively after $72 \mathrm{hr}$. On the other hand, the highest growth (0.347) and the lowest growth (0.319) as O.D. (750 nm) of Nostoc spongiaeforme were found at $1 \mathrm{x}$ and $2 \mathrm{x}$, respectively after $48 \mathrm{hr}$. The highest growth (0.536) and the lowest growth (0.515) as O.D. were found at $1 \mathrm{x}$ and $1.5 \mathrm{x}$, respectively after $72 \mathrm{hr}$. Miller et al. (1999) found that the increased nutrient concentration in medium resulted in better growth and higher biomass of blue green algae.

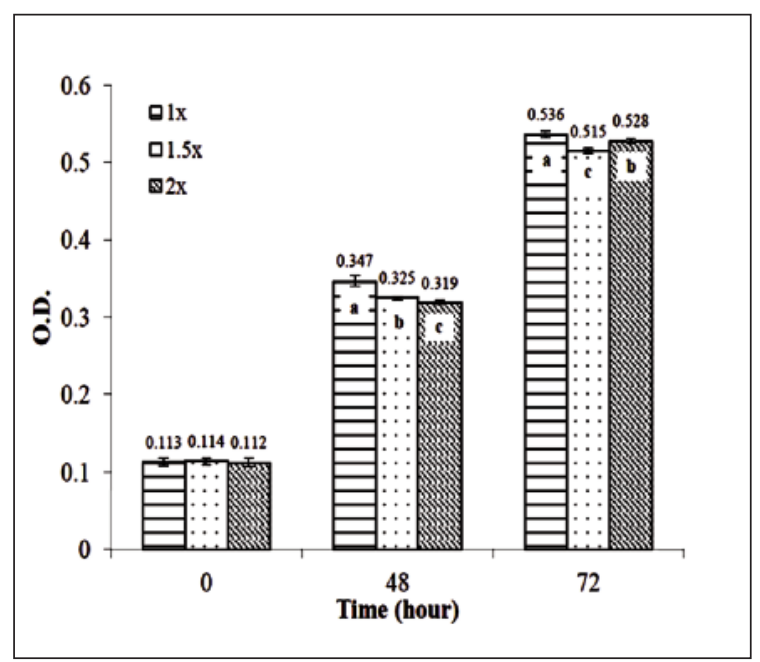

Fig. 12. Effect of nutrient concentration in medium on the growth as O.D. of Nostoc spongiaeforme

Air bubbling on growth

The effect of air bubbling on growth of Chlamydomonas noctigama and Nostoc spongiaeforme as O.D. (750 nm) was presented in Fig. 13.

The growth as O.D. of Chlamydomonas noctigama and Nostoc spongiaeforme with and without air bubbling were 


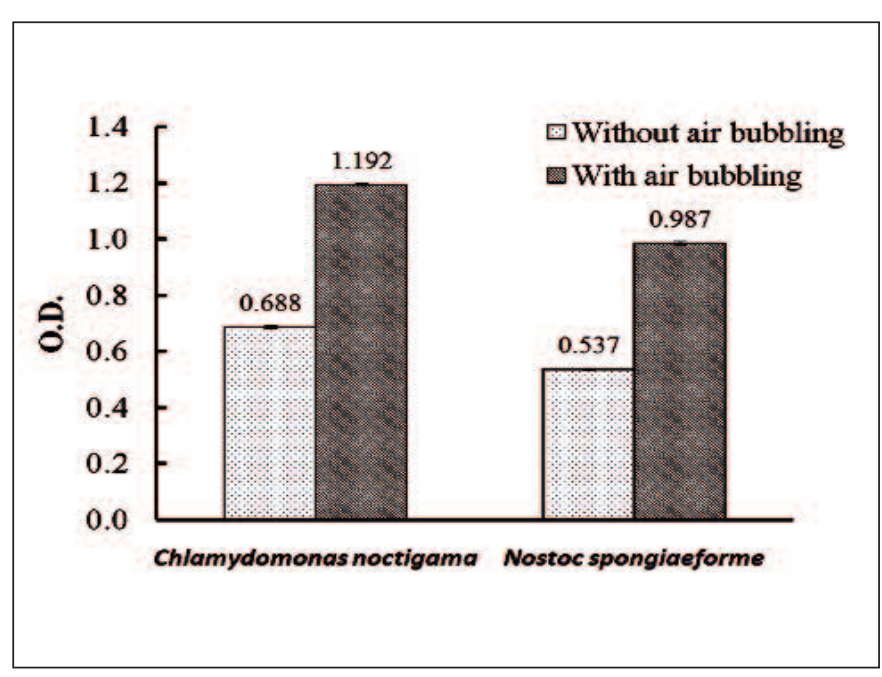

Fig. 13. Effect of air-bubbles supply on the growth as O.D. (at $750 \mathrm{~nm}$ ) of Chlamydomonas noctigama and blue-green algae Nostoc spongiaeforme.

statistically different from each other at 5\% level. An increase of $73 \%$ and $84 \%$ in the growth of the green alga and blue green alga, respectively was observed. It appears that both the isolates were responsive to air bubbling. It might be due to the utilization of $\mathrm{CO}_{2}$ required for photosynthesis. Similar findings were reported by Evjen (2014) and Hassan et al. (2012) on Chlamydomonas reinhardtii and Nostoc muscorum.

\section{Conclusion}

The randomly isolated and selected algal strains in the present investigation i.e. Chlamydomonas noctigama and Nostoc spongiaeforme showed variable growth conditions and can be taken as baseline conditions. If growing in the optimum conditions, the algal strains can be used as a source of biomass for biofuel and other valuable products. Further research for large scale biomass production using the sets of growth conditions in raceway ponds and/or photo-bio reactor is required.

\section{Acknowledgment}

The authors would like to thank the Centre for Advanced Studies and Research in Biological Sciences, University of Dhaka for financial support and the Department of Botany, University of Dhaka for providing necessary lab facilities, in particular, giving access to the growth room and analysis of the morphological characteristics of the isolates.

\section{References}

Ahmed ZU, Begum ZNT, Hassan MA, Khondker M, Kabir SMH, Ahmed M, Ahmed ATA, Rahman AKA and Haque EU (eds.). (2008), Encyclopedia of Flora and Fauna of Bangladesh. Vol. 3. Algae, Chlorophyta (3). Asiatic Society of Bangladesh, Dhaka. 591-592.

Akimoto M, Yamada H, Ohtaguchi K and Koide K (1997), Photoautotrophic cultivation of the green alga, Chlamydomonas reinhardtii as a method for carbon dioxide fixation and alpha-linolenic acid production. J. Am. Oil Chem. Soc. 74: 181 - 183.

APHA (1985), Standard Methods for the Examination of Water and Wastewater. American Public Health Association. Washington D. C. 268.

Aziz A and Whitton BA (1987), Morphogenesis of BlueGreen Algae. I. Filament Development in Gloeotrichia. Bangladesh J. Bot. 16(1): 69-81.

Croft MT, Warren MJ and Smith AG (2006), Algae need their vitamins. Eukaryot Cell. 5: 1175-1183.

Evjen ME (2014), Effects of daylight and high light periods on growth and quality of the green microalga Chlamydomonas reinhardtii. Master thesis. Norwegian University of Life Sciences. 3-81.

Gensemer RW, Smith REH, Duthie HC and Schiff SL (1993), pH tolerance and metal toxicity in populations of the planktonic diatom Asterionella- Influences of synthetic and natural dissolved organic carbon. Can. J. Fish. Aquat. Sci. 50: 1812.

Granhall U (1975), Nitrogen fixation by blue-green algae in temperate soils. In Nitrogen fixation by free-1iving microorganisms, Stewart, W. D. P. (ed.). Cambridge University Press. 189-197.

Hannon M, Gimpel1 J, Tran M, Rasala1 B and Mayfield S (2010), Biofuels from algae: challenges and potential. Biofuels. 1(5): 763-784.

Harris EH (2009), The Chlamydomonas Sourcebook. Oxford, GB: Academic Press, Elsevier.129-135. 
Hassan SH, Hameed MSA, Hammouda OE, Ghazal FM and Hamed SM (2012), Effect of different growth conditions on certain biochemical parameters of differentcyanobacterial strains. Malays. J. Microbiol. 8(4): 266272.

Kratz WA and Myers J (1953), Nutrition and growth of several blue-green algae. Am. J. Bot. 42: 282-287.

Lang I, Gobel C, Porzel A, Heilmann I and Feussner I (2008), A lipoxygenase with linoleate diol synthase activity from Nostoc sp. PCC 7120. Biochem J. 410(2): 347-57.

Laurinavichene T, Tolstygina I and Tsygankov A (2004), The effect of light intensity on hydrogen production by sulfur-deprived Chlamydomonas reinhardtii. Biotechnol. 114(1-2): 143-151.

Li-Juan Z, Xiao-Jun Y, Guan-YiNi S (2011), Optimum temperature and light conditions for culturing Nostoc commune and their effects on the functional compound scytonemin. Food Sci. 32(9): 208-212.

Marker AFH, Nusch EA, Rai H and Rieman B (1980), The measurement of photosynthetic pigments in freshwater and standardization of methods: conclusions and recommendations. Arch. Hydrobiol. Beih. Ergebn. Limnol. 14: 91-106.

McVeigh I and Brown WH (1954), In vitro Growth of Chlamydomonas chlamydogama Bold and Haematococcus pluvialis Flotow em. Wille in Mixed Cultures Bulletin. Torrey Bot.Club. 81(3): 218.

Miller MW, Hay M E, Miller SL, Malone D, Sotka EE and Szmant AM (1999), Effect of nutrients versus herbivores on reef algae: a new method for manipulating nutrient on coral reef. Limnol. Oceanogr. 44: 18471861.

Pankaj VP and Awasthi M (2015), Microalgae biofuel can be easy available source of energy. Int. J. Innov. Sci. Eng. Technol. 2(2): 303-308.

Pocock T, Lachance M, Pröschold T, Priscu JC, Sulgi S, Norman K and Huner P A (2004), Identification of a psychrophilic green alga from Lake Bonney Antarctica: Chlamydomonas raudensis Ettl. (UWO
241) Chlorophyceae. J. Phycol. 40: 1138-1148.

Qudus NA and Halim SZA (2012), Techno-Economic Assessment of Algae Bio-Fuel Production in Bangladesh. Department of Mechanical Engineering, BUET. pp 1-49

Rodolfi L, Zittelli G.C, Bassi N, Padovani G, Biondi N and Bonini G (2009), Microalgae for oil: strain selection, induction of lipid synthesis and outdoor mass cultivation in a low- cost photobioreactor. Biotechnol. Bioeng. 102(1): 100-12.

Rodriguez H, Rivas J, Guerrero MG and Losada G (1986), Selection of nitrogen-fixing blue- green algae for biomass photoproduction. In Proceedings of the 1986 International Congress on Renewable Energy. Vol.1, Consejo Superior De Investigaciones Cientificas, Madrid, Spain. 183-186.

Schenk P, Thomas-Hall S, Stephens E, Marx U, Mussgnug J, Posten C, Kruse O and Hankamer B (2008), Second Generation Biofuels: High-Effiency Microalgae for Biodiesel Production. Bioenergy Res. 1: 20-43.

Siddiqui KU, Islam MA, Ahmed ZU, Begum ZNT, Hassan MA, Khondker M, Rahman MM, Kabir SMH., Ahmed M, Ahmed ATA, Rahman AKA. and Haque EU (eds.). (2007), Encyclopedia of Flora and Fauna of Bangladesh. Vol. 2. Cyanobacteria, Bacteria and Fungi. Asiatic Society Bangladesh, Dhaka. 87-88.

Sinclair C and Whitton BA (1977), Influence of Nutrient Deficiency on Hair Formation in the Rivulariaceae. Br. Phycol. J. 12: 297-313.

Skjanes K, Knutsen G, Kallqvist T and Lindblad P (2008), $\mathrm{H}_{2}$ production from marine and freshwater species of green algae during sulfur deprivation and considerations for bioreactor design. Int. J. Hydro. Energ. 33(2): 511-521.

Spencer DF, Liow P and Lembi CA (2011), Growth response to temperature and light in Nostoc spongiaeforme (Cyanobacteria). J. Freshwater Ecol. 26(3): 357-363.

Received: 27 January 2016-; Revised: 03 March 2016; Accepted: 24 April 2016. 